\title{
SUBJETIVIDADE, CULTURA E EDUCAÇÃO EM HERBERT MARCUSE
}

\author{
Subjectivity, Culture and Education in Herbert Marcuse \\ Subjetividad, Cultura y Educación en Herbert Marcuse \\ Subjectivite, Culture et Éducation en Herbert Marcuse
}

Vivian Baroni

Mestre e doutoranda em Educação pelo Programa de Pós-graduação em Educação - Universidade de Passo Fundo.

Recebido em: 09/02/2015 / Revisado em: 24/08/2015 / Aceito em: 10/12/2015

\section{Resumo}

A filosofia de Herbert Marcuse, profundamente marcada pela dialética hegeliana, representa uma poderosa ferramenta de análise do panorama da dominação sócio-econômica do sistema capitalista, apontando, contudo, para o potencial emancipatório inerente à dimensão estética. Sua contundente análise da sociedade industrial, que difere consideravelmente da interpretação marxista, insiste em apontar para os efeitos da superestrutura sobre a estrutura, confirmando a influência determinante da consciência nos processos de transformação social. Assim, para Marcuse, uma transformação subjetiva deve obrigatoriamente preceder uma transformação mais geral nas condições propriamente objetivas da sociedade. Valendo-nos da bibliografia de Marcuse, no presente artigo procuraremos explicitar de que forma as normas e valores da sociedade estabelecida podem ser introjetados na subjetividade dos indivíduos, consubstanciando, por sua vez, um conceito repressivo de razão. Procuramos ainda ressaltar a possibilidade de superação desse estado, que na obra marcuseana é representada pela valorização dos âmbitos teóricos do pensamento, da arte e da cultura autêntica, como esferas que podem romper a consciência reificada para então conduzir a um conceito crítico de razão. Esse processo de libertação subjetiva é levado a cabo por uma educação estética que, no contato com a arte, possibilita um conceito de educação como formação que sensibiliza e impele à práxis transformadora.

Palavras-chave: Marcuse; subjetividade; educação; libertação.

\begin{abstract}
Herbert Marcuse's philosophy, deeply marked by Hegelian dialectics, represents a powerful tool for analyzing the panorama of the socioeconomic domination of the capitalist system, pointing, however, to the emancipatory potential inherent in the aesthetic dimension. His strong analysis of industrial society, which differs considerably from the Marxist interpretation, insists on pointing to the effects of the superstructure on structure, confirming the determining influence of consciousness in the processes of social transformation. Thus, for Marcuse, a subjective transformation must precede a more general transformation in the properly objective conditions of society. Using Marcuse's bibliography, in this article we will try to explain how the norms and values of the established society can be introjected in the subjectivity of the individuals, consubstantiating, in turn, a repressive concept of reason. We also try to emphasize the possibility of overcoming this state, which in the work Marcusean is represented by the valorization of the theoretical spheres of thought, art and authentic culture, as spheres that can break the reified consciousness and then lead to a critical concept of reason. This process of subjective freedom is carried out by an aesthetic education which, in contact with art, enables a concept of education as a formation that sensitizes and impels the transforming praxis.
\end{abstract}

Keywords: Marcuse; subjectivity; education; liberation. 


\section{Resumen}

La filosofía de Herbert Marcuse, profundamente marcada por la dialéctica hegeliana, representa una poderosa herramienta de análisis del panorama de la dominación socio-económica del sistema capitalista, indicando, no obstante, para el potencial de emancipación inherente a la dimensión estética. Su contundente análisis de la sociedad industrial, que se diferencia considerablemente de la interpretación marxista, insiste en señalar para los efectos de la superestructura sobre la estructura, confirmando la determinante influencia de la conciencia en los procesos de transformación social. Así, para Marcuse, una transformación subjetiva debe obligatoriamente preceder a una transformación más general en las condiciones propiamente objetivas de la sociedad. Valiéndonos de la bibliografia de Marcuse, en este artículo buscaremos explicitar de qué forma las normas y valores de la sociedad establecida pueden ser introyectados en la subjetividad de los individuos, consolidando, a su vez, un concepto represivo de razón. Buscamos aún resaltar la posibilidad de superación de este estado, que en la obra marcuseana es representada por la valoración de los ámbitos teóricos del pensamiento, del arte y de la cultura auténtica, como esferas que pueden romper la consciencia rectificada para entonces conducir a un concepto crítico de razón. Este proceso de liberación subjetiva es llevado a cabo por una educación estética que, en el contacto con el arte, posibilita un concepto de educación como formación que sensibiliza e impele a la praxis transformadora.

Palabras clave: Marcuse; subjetividad; educación; liberación.

\section{Résumé}

La philosophie de Herbert Marcuse, est profondément marquée par la dialectique hégélienne, et représente un outil puissant d'analyse du panorama de la domination socio-économique du système capitaliste, pointant vers le potentiel d'émancipation inhérent à la dimension esthétique. Son analyse incisive de la société industrielle, qui diffère considérablement de l'interprétation marxiste, attire l'attentions sur les effets de la superstructure sur la structure, ce qui confirme l'influence décisive de la conscience dans les processus de transformation sociale. Donc, pour Marcuse, une transformation subjective doit, obligatoirement, précéder une transformation plus générale chez les conditions proprement objectives de la société. À l'aide de la bibliographie de Marcuse, nous allons essayer d'expliquer comment les normes et les valeurs de la société établie peuvent être mis dedans la subjectivité des individus, en matérialisant, à son tour, une conception répressive de la raison. Nous voulons aussi mentionner la possibilité de surmonter cet état, qui, sur le travail de Marcuse, est représenté par la valorisation des champs théoriques de la pensée, de l'art et de la culture authentique, comme des sphères qui peuvent briser la conscience et aprés, conduire à une conception critique de la raison. Ce processus de libération subjective est effectué par une éducation esthétique qui, au contact avec l'art, permet un concept d'enseignement comme une formation qui sensibilise et conduit à la pratique transformatrice.

Mots-clés: Marcuse; subjectivité; éducation; libération.

Frente ao crescente desenvolvimento da moderna sociedade pós-industrial, a possibilidade de pacificação da luta pela existência torna-se tangível, porém, a ênfase exacerbada no lucro e no crescimento quantitativo faz com que o desenvolvimento humano seja minimizado em prol da lucratividade do sistema econômico. A análise marcuseana aponta para esta direção, sugerindo, no entanto, um importante aspecto até então não considerado em todo o seu alcance pelo marxismo: o papel da subjetividade na construção e na transformação da realidade. Retomando a dialética hegeliana, a subjetividade, para Marcuse, representa tanto a possibilidade histórica da continuidade do atual sistema de servidão pela manutenção da subjetividade repressiva, como a possibilidade de reconstrução da realidade a partir de conceitos inerentes à dimensão estética, conduzindo, por sua vez, a uma redefinição da cultura.

Em sua análise acerca da sociedade industrial em ascensão, Marcuse procurou demonstrar como a realidade de sua época, marcada pela irracionalidade dos gastos militares, pelo crescente poder econômico sobre a existência dos sujeitos e pela reificação dos âmbitos da vida social, estão ligados ao conceito repressivo de razão adotado pela civilização, sendo sua representação máxima o sistema capitalista. Nestes termos, o que passa a ser considerado válido pela racionalidade subjacente à sociedade moderna são os modos de pesquisa e desenvolvimento baseados nas premissas do positivismo e do crescimento quantitativo. A esfera da cultura não deixa de sentir essas mudanças no campo social e econômico e, dessa maneira, deixa-se influenciar pelas tendências mercadológicas, cuja principal consequência é a perda do elemento de negação presente nas obras artísticas. Ou seja, a cultura perde a capacidade de se posicionar contrariamente as forças dominantes que dirigem o progresso técnico e social.

Porém, se a origem da reificação e da servidão humana encontra-se no conceito de razão empregado pela sociedade, uma 
mudança na sua concepção poderia reverter a direção do progresso, iniciando um movimento em direção ao desenvolvimento qualitativo. Neste sentido, a dimensão estética aliada a um programa de educação voltado para o fomento do pensamento negativo, torna-se um fator fundamental no programa de redefinição da cultura, pois representa o contraponto teórico necessário para se transcender a racionalidade instrumental vigente. Nesse sentido, a teoria de Marcuse, ao ser reapropriada e trabalhada em outras dimensões e em consonância com as mudanças históricas, pode promover o debate contemporâneo sobre a dominação e emancipação nas sociedades avançadas, fomentando novos olhares aos problemas atuais a partir da perspectiva da tradição da teoria crítica.

Seguindo esta perspectiva, no presente artigo procuraremos investigar de que forma se dá a construção repressiva da subjetividade no contexto de uma racionalidade instrumental, assim como apontar as possibilidades de transcendência dessa condição, que a nosso ver, se substancia no conceito de educação estética. Trabalhamos com a hipótese de que em virtude do poder da crítica e do pensamento negativo inerente à arte, a educação estética teria um papel fundamental na reconstrução do conceito de racionalidade vigente na sociedade tecnológica, que por sua vez, voltaria suas forças para o livre desenvolvimento humano.

\section{A Sociedade Unidimensional: Racionalismo, Princípio da Realidade e Falsas Necessidades}

Distanciando-se do conceito de razão inerente ao pensamento iluminista, Marcuse buscou em seus escritos mostrar a faceta negativa do progresso técnico, o que o levou a debater as consequências do pessimismo cultural de Freud, sem tomar uma síntese como finalizada. Marcuse via na psicanálise freudiana a possibilidade de explicação da solidez da repressão exercida pela sociedade como sendo causa de uma administração científica das necessidades instintuais. No entanto, como é o caso específico do conceito de Eros e sua relação com a civilização, fica clara a necessidade de se manter a dialética dos conceitos freudianos que sofreram uma transformação histórica. Assim, é em uma de suas mais importantes obras, Eros e civilização, que Marcuse (1975) faz uma tentativa de reinterpretação da dinâmica social do princípio da realidade, procurando demonstrar seu caráter histórico.

Nesse livro, Marcuse contrapõe a abordagem freudiana do princípio da realidade, que afirma a impossibilidade da superação da repressão (Freud, 1930/2010), com uma historicização dos conceitos freudianos, mostrando como o progresso técnico e científico atuais permitem uma maior liberação da renúncia instintual, comparativamente aos períodos históricos de maior escassez de recursos tecnológicos. No entanto, a sociedade e a forma como está organizada a manutenção das estruturas de poder, impede que esse estado seja transcendido, visto que o sistema econômico se baseia precisamente na sujeição instintual e na manutenção das falsas necessidades.

O princípio da realidade refere-se à exigência de se tomar o controle sobre o mundo natural para que a civilização apareça, a sujeição dos impulsos básicos em favor da convivência em grupo e, consequentemente, a repressão do princípio do prazer em prol da sobrevivência, a adaptação do sujeito à realidade, assim como o abandono das possibilidades de satisfação pulsional em prol do surgimento da sociedade. A razão, neste caso, é motivada para a tendência a separar o "bom" do "ruim", assim como a associar o "bom" ao "útil". No entanto, na sociedade industrial avançada, o princípio da realidade aparece como diretamente dependente do sistema econômico de produção, o que faz com que este adquira as características da sociedade em que se insere, modificando o grau de importância vital do princípio do desempenho.

Aqui Marcuse sugere que o princípio do desempenho não é imutável, mas adquire um caráter histórico específico no decorrer do tem. Dessa maneira, Marcuse conduz uma análise que deriva das noções e preposições de Freud, nas quais os processos históricos se apresentam como processos biológicos. A argumentação segue por uma linha básica que considera o argumento freudiano da repressão básica e sua necessidade como falacioso "na medida em que se aplica ao fato concreto da carência, que na realidade é a consequência de uma organização específica da carência e de uma igualmente específica atitude existencial, imposta por essa organização" (Marcuse, 1975, p.51). A historicização da teoria requer, contudo, uma duplicação dos conceitos, na qual os termos freudianos de repressão e princípio da realidade devem ser emparelhados com os seus correspondentes histórico-sociais específicos: mais-repressão, as restrições requeridas pela dominação social, e princípio do desempenho, a forma histórico-contemporânea assumida pelo princípio da realidade.

Considerando o fato de que o princípio da realidade se desenvolve em uma sociedade que retém a possibilidade de eliminação gradual da labuta e da luta pela existência, a forma como ele se apresenta na contemporaneidade é designada por Marcuse como princípio do desempenho, pois sob seu domínio a sociedade é necessariamente estratificada de acordo com os desempenhos econômicos concorrentes entre os seus membros. Representativo de uma sociedade acumuladora e em permanente expansão, pressupõe a dominação racionalizada, ou seja, a estrutura do trabalho encarrega-se de reproduzir a sociedade sob condições progressistas. A energia instintiva reprimida pelo processo de produção, Eros, é dirigida para a utilização social através da internalização da autoridade na própria consciência do indivíduo, fazendo-a operar como seu 
próprio desejo, sua moralidade e satisfação (Marcuse, 1975).

Evidentemente, Marcuse não nega a necessidade de uma repressão fundamental das pulsões. O que aparece como paradoxal é que o desenvolvimento avançado da sociedade sob a égide do princípio do desempenho tenha alcançado um tal índice de produtividade que as exigências sociais instintivas consumidas em trabalho alienado podem ser consideravelmente reduzidas, dando condições para a superação do princípio da realidade repressivo. O fato desse estado não ter se efetivado, mas até mesmo a dominação ter se intensificado, justifica-se por uma carga extra de repressão que é acrescentada ao princípio do desempenho. A isso Marcuse denomina mais-repressão, ou seja, controles adicionais acima e além dos indispensáveis à associação humana civilizada que são introduzidos pelas várias instituições históricas específicas do princípio da realidade e pelos interesses específicos da dominação (Marcuse, 1975).

Essa racionalidade da dominação preserva ainda a carência, e escassez e a coação. Conforme Carnaúba (2009), com o conceito de mais-repressão, Marcuse enfatiza o elemento crítico que teria faltado na teoria freudiana, ou seja, a consideração da distinção entre as exigências do princípio da realidade e as exigências de uma forma específica de dominação impostas por uma realidade determinada.

Um conceito importante que completa essa abordagem psicanalítica da dominação é extraído de Marx que aparece no texto Contribuição à crítica da economia política (Marx, 2008), e que terá importância fundamental no pensamento de Marcuse, é o de racionalismo, isto é, a tendência das sociedades modernas à administração total, à planificação de todos os setores da vida, à quantificação. Essa quantificação, que tem origem com a mercantilização, relaciona-se diretamente com o conceito de princípio do desempenho, que exige bem mais do que a estrita adaptação ao princípio da realidade e a satisfação das necessidades básicas. Dessa forma, a sociedade exige uma submissão à rentabilidade econômica que se traduz no sacrifício injustificado do tempo livre e no investimento desmedido da energia pulsional no trabalho. Essa relação do indivíduo com os meios de produção gera também uma racionalidade característica desse princípio do desempenho.

Encontra-se aqui a linha principal de argumentação a ser seguida por Marcuse em sua obra mais famosa, A ideologia da sociedade industrial: o homem unidimensional (Marcuse, 1978). Nesse livro, Marcuse procura mostrar como o conceito de razão empregado pela moderna sociedade industrial na verdade possui apenas um caráter irracional. O caráter contraditório da sociedade moderna torna-se evidente: enquanto de um lado a tecnologia deve ser desenvolvida com o objetivo de proporcionar o aumento da qualidade de vida e atender às necessidades crescentes da população, por outro lado, essa industrialização extrema deve ser refreada na tentativa de impedir que a tecnologia torne possível a libertação dos indivíduos.

A forma como a sociedade organizou o aparato tecnológico demostra seu caráter totalitário. Como afirma Marcuse (1978, p. 23), "uma falta de liberdade confortável, suave, razoável, democrática prevalece na civilização industrial desenvolvida, um testemunho do progresso técnico". A liberdade da fase inicial do capitalismo perdeu seu sentido lógico e conteúdo tradicional de forma que a sociedade pode exigir a aceitação de seus princípios em troca de um padrão de vida crescente, pois "parece fazer pouca diferença o ser a crescente satisfação das necessidades conseguida por um sistema totalitário ou não-totalitário" (Marcuse, 1978, p. 24).

Marcuse aponta para o conceito de falsas necessidades como a forma de guerra mais eficaz e resistente contra a libertação, pois atua de forma a perpetuar formas obsoletas de luta pela existência. As falsas necessidades são aquelas impostas ao indivíduo com o claro interesse de reprimi-lo, determinadas e condicionadas por forças exteriores sobre as quais o sujeito não tem controle algum. É através delas que a base para o consumo (elemento central do atual sistema econômico) é perpetuada em larga escala, pois sob seu jugo o sujeito é impedido até mesmo de decidir a cerca das suas reais necessidades (as necessárias para a manutenção básica da vida) e daquelas que são criadas com a intensão principal de perpetuar a sua servidão. Desta forma, toda a sua possibilidade de liberdade individual é resume-se ao consumo e identificação com as novas necessidades, incitando à fascinação irracional que gera o consumo máximo das mercadorias disponibilizadas pelo mercado.

A satisfação dessas falsas necessidades pode ser tomada por algo extremamente agradável, porém, a manutenção da felicidade do indivíduo não é uma condição a ser mantida quando essa mesma felicidade serve para desenvolver a aptidão em reconhecer a moléstia do todo e aproveitar as oportunidades de cura (Marcuse, 1978). As falsas necessidades são imprescindíveis à manutenção do sistema: são as responsáveis por incentivar o consumo desnecessário e fútil, difundir ideologias capitalistas, assim como tolher a capacidade crítica do sujeito a fim de mais facilmente poder constituir sua subjetividade segundo parâmetros próprios. A imposição é feita pelo condicionamento através do consumo, tanto de bens materiais quanto culturais. $\mathrm{O}$ fato de elas serem consideradas como necessárias e imperiosas pelos sujeitos reflete apenas a constatação de serem ou não desejáveis para as instituições sociais comuns. Essas necessidades continuam a pertencer a uma sociedade cujo interesse dominante exige a repressão

Marcuse aponta para o fato de que tais necessidades repressivas são aceitas pelo indivíduo na ignorância e na derrota, porém, o reconhecimento de sua situação é requisito básico para a emancipação daqueles cuja miséria é o preço de sua satisfação. Segundo Marcuse (1978), as únicas necessidades que teriam direito indiscutível à satisfação seriam as necessidades vitais, ou seja, aquelas das quais dependeria a satisfação de todas as outras, sublimadas ou não. Porém, a distinção entre as 
que realmente são imprescindíveis ao indivíduo e a uma boa qualidade de vida, das que são falsas necessidades, responsáveis pelo aprisionamento da subjetividade, só em último caso pode ser realizada pelo próprio sujeito: quando este se apresentar totalmente livre de doutrinação, manipulação ou ideologia de qualquer espécie.

\section{Cultura e Civilização: A Racionalização da Cultura}

Pode-se dizer que o foco do livro A ideologia da sociedade industrial (Marcuse, 1978) é problema da razão que se transforma em racionalismo. De que forma isso acontece? Quais são os motivos que levam a tal transformação? Nesse livro, Marcuse aponta como causa a separação entre Logos (razão ou conhecimento racional) e Eros (energia sensual, dinâmica) na construção da racionalidade social. Conforme Marcuse é essa união original do Logos com Eros que mantem ordenado o mundo: "os dois termos designam duas modalidades de negação; a cognição, tanto erótica como lógica, rompe a influência da realidade estabelecida e contingente e luta por uma verdade incompatível com ela" (Marcuse, 1978, p. 128). Porém, tal dinâmica se vê ameaçada na medida em que o caráter cotidiano da vida, da provisão material e da necessidade impossibilita a fruição exigida por Eros. Também nas ciências, a separação da razão do emocional se torna cada vez mais visível. E desde que a expressão do Logos, da palavra, é mais manejável que as emoções, o estudo deste tomará um lugar importante no desenvolvimento da filosofia ocidental.

Não demora muito para que se dê a transformação do Logos em lógica através da perda de contato com o real, fazendo com que a palavra se tranque num universo separado daquele em que surgiu, sendo regida por leis formais independentes da situação a que se aplicam (Doria, 1974). Conforme Marcuse (1978), a linguagem presencia a unificação e identificação, a produção sistemática do pensamento nos moldes do positivismo. Nessas condições, os elementos de autonomia e crítica são eliminados através da designação, asserção e imitação sistemáticos impostos pelos "hábitos de pensar" social.

A linguagem unidimensional atua de forma a esconder a representação linguística autêntica, tornando-a um objeto do operacionismo, que visa tornar um conceito como sinônimo da operação correspondente. A real função é direcionar a palavra para um significado único que não transgrida o comportamento anunciado e padronizado de antemão. Nesse caso, "os nomes das coisas não são apenas indicativos do modo de funcionar, mas sua maneira (real) de funcionar também define e fecha o significado da coisa, excluindo outras maneiras de funcionar" (Marcuse, 1978, p. 94).

Quando essa condensação da palavra trata de conceitos ou ocorrências mais amplas que objetos ou coisas de uso cotidiano, a mutilação da linguagem passa a ser de ordem política. O nome que é dado à palavra não define somente seu modo de funcionar, mas também fecha seu universo de possibilidades, tornando a sentença uma mera declaração a ser aceita. Marcuse atenta para o fato de algumas dessas expressões serem usadas como "fórmulas mágicas", que tem como principal função o fechamento do universo da locução em torno do termo escolhido para representa-lo, um termo que corresponda à função desejada pelo sistema para manter ou inculcar normas e valores correspondentes à sociedade industrial. "A estrutura analítica isola o substantivo governante de seus conteúdos que invalidam ou pelo menos perturbariam o uso aceito do mesmo em declarações políticas e na opinião pública. O conceito ritualizado é tornado imune à contradição" (Marcuse, 1978, p. 96).

Ainda, o fato de um substantivo ser quase sempre ligado aos mesmos adjetivos serve para que não restem dúvidas acerca do real significado da palavra. Essa é a técnica utilizada pela indústria da propaganda, a repetição de uma sentença ad nausean que, ligada a um determinado produto, fixa o significado na mente do indivíduo, sendo extremamente eficaz em estabelecer uma imagem ideal que ajuda a vender mercadorias. As sentenças são agrupadas em torno de linhas de impacto e incitadores de audiência, que tem a função de relacionar a palavra ou imagem de impacto com a mercadoria, sendo associada imediatamente quando vistas (Marcuse, 1978).

Dentro do esquema abrangente que tem como meta a constituição da subjetividade em prol do sistema capitalista, a produção abarcada pelo processo positivista impõe sua influência aos homens através da relação direta que estes apresentam com os objetos da produção, difundindo sua ideologia através da imposição de um ritmo e forma de produzir que cria valores e comportamentos condizentes com a manutenção do sistema. Não se pode negar que daí também se desprende uma cultura com a forma e o caráter do sistema capitalista, imbuída do objetivo primeiro de, juntamente com as relações de produção, exercer um domínio sobre o indivíduo de forma a condicionar suas necessidades em favor da manutenção do status quo.

A produção cultural sempre foi considerada uma esfera à parte da produção material do homem e sua consequente incorporação pela sociedade um problema. Desde a antiguidade clássica, a arte é considerada como uma esfera independente das relações sociais, vista como um mundo "ideal", na medida em que se situa além da esfera das necessidades e da provisão material. Esta separação entre o útil e o necessário do belo e da fruição, segundo Marcuse, constitui o início de um desenvolvimento que se volta para o materialismo da práxis burguesa por um lado e, por outro, para o aprisionamento da felicidade e da fruição em um plano à parte da cultura, completamente isolado do plano material, caracterizando toda a atividade de provisão das necessidades como má, feia e essencialmente não-verdadeira (Marcuse, 1997). 
Marcuse (1997) chama de cultura afirmativa aquela que leva à distinção entre mundo material e mundo anímico, considerando este último como uma esfera de valores autônoma em relação à civilização, mais valiosa e essencialmente diferente do mundo da luta diária pela existência. Esse tipo de cultura afirma ser possível a qualquer um alcançar esse universo transcendente "a partir do interior", sem a transformação da realidade exterior. A ênfase na alma possibilita a fruição e a transcendência individual, afirmando um mundo interior puro e autônomo que não pode ser atingido pela dor e a miséria do mundo exterior.

Porém, tal distinção entre civilização, como mundo da provisão material da vida, e cultura, como mundo espiritual interior, não trata apenas de simples separação entre o necessário e o belo, pois na medida em que esses valores são convertidos e interiorizados no cerne dos valores culturais, "erige-se na cultura um reino de aparente unidade e aparente liberdade, onde as relações existenciais antagônicas devem ser enquadradas e apaziguadas. A cultura refirma e oculta as novas condições de vida" (Marcuse, 1997, p. 96). Com a consolidação do capitalismo, os valores da cultura burguesa passam a servir aos desígnios da sociedade industrial. A ideia de um mundo interior totalmente autônomo em relação ao mundo exterior serve para submeter mais facilmente o homem, fazendo com que se curve mais humildemente ao destino e obedeça mais a autoridade. Enquanto o indivíduo sofre as intempéries da provisão das necessidades, a alma permanece pura e intocada, fortalecida ainda mais pelas provas dadas pelo destino.

Justamente pela cultura superior representar uma "outra dimensão" essencialmente diferente desta, é que seu caráter de negação e contestação da realidade, seus elementos transcendentes, são desbastados. Esse processo ocorre através da sua incorporação na ordem vigente pela massificação e difusão em larga escala, transformando a cultura em mercadoria e sujeitando-a as leis do mercado. Diante das massas, a quantidade se tornou qualidade em virtude do aumento maciço de participantes que transforma inegavelmente a função e o conteúdo da arte. Como afirma Benjamim (1982, p.237), "as massas buscam diversão, mas a arte exige recolhimento". Na obra de arte é o sujeito que penetra nela, frui através dela. Na diversão ocorre o contrário, é a obra de arte que penetra nas massas.

Marcuse aponta para a importância das obras artísticas superiores estarem a disposição de todos, porém, no mesmo instante em que são difundidos em larga escala, tornam-se "dentes de engrenagem de uma máquina da cultura que refaz seu conteúdo" (Marcuse, 1978, p.77). A difusão de obras clássicas pode mostrar a falha de uma sociedade que permitia somente a uns poucos privilegiados o benefício da fruição da alta cultura, porém, esse fato não é corrigido com a massificação, que só tem por resultado a destruição da real função da arte: seu caráter de recusa. A incorporação da arte na decoração da casa e da empresa, nos programas de entretenimento e nas novelas suprime sua função tradicional: "se convertem em afirmativos, ou seja, servem para fortalecer o domínio do Sistema estabelecido sobre o espírito (...) e contribuem para reforçar o domínio do que é sobre o que pode ser e sobre o que deve ser" (Marcuse, 1986, p.62, grifos do autor).

$\mathrm{O}$ fechamento da dimensão antagônica da cultura representa o fechamento de um espaço vital onde se desenvolvia a autonomia e a reflexão que até então podiam fazer frente ao totalitarismo experimentado pela sociedade capitalista. Através do operacionismo, os elementos negativos são integrados ao positivo, eliminando a dialeticidade da cultura. Tal operacionismo nos termos transcendentes da cultura não representa somente um processo metodológico, mas sim um processo social e político.

A consequência gerada por esse processo de inclusão dos valores culturais na sociedade é a obliteração da alienação da cultura da civilização, eliminando, consequentemente, a tensão entre o que "é" e o que "deve" ser, o possível e o atual, a liberdade e a necessidade (Marcuse, 1986). Os conteúdos autônomos e críticos da cultura são aplainados e convertidos em conteúdos educativos, subliminares e relaxantes, tendo como objetivo servirem de veículo de adaptação.

\section{A Necessidade de uma Nova Sensibilidade como Caminho para uma Nova Educação e Emancipação Humana}

A incorporação da arte à cultura de massa contribui para a eliminação de uma esfera crítica em relação à civilização, e resulta em último caso, em um pensamento unidimensional, incapaz de transcender a realidade, alterando a relação entre cultura e civilização. Esse fato aparece como um reflexo direto dos processos racionais avançados da sociedade industrial, que em curso desde o Iluminismo, tomam a forma contemporânea de um racionalismo exacerbado. A racionalidade científica, atingindo o auge da mecanização de todo o trabalho socialmente necessário, mas individualmente repressivo, acaba por abarcar também a cultura enquanto arte autônoma, bloqueando seu caráter utópico e integrando-a na estrutura totalitária que governa os homens. Nas palavras de Marcuse (1978, p.212), "a racionalidade da dominação separou a Razão da ciência e a Razão da arte, ou, ela falsificou a Razão da arte pela integração da arte no universo da dominação".

Essa relação deficiente entre cultura e civilização é fruto da sociedade tecnológica que, na medida em que avança, vai exigindo um alto grau de racionalização. A absorção administrativa da cultura pela civilização é o resultado de uma 
orientação estabelecida unicamente pelo progresso científico e técnico, a conquista repressiva da natureza e do homem, e a utilização constante do crescente nível de vida para perpetuar sua organização de luta permanente para a satisfação das necessidades (Marcuse, 1986). Logo, para Marcuse, a causa do aprisionamento do indivíduo sob formas repressivas de existência estaria ligada diretamente à concepção de razão que perpassa a racionalidade cientifica moderna. Por conseguinte, uma mudança na concepção de razão é também capaz de alterar a natureza das instituições que compõe a moderna sociedade industrial. Conforme Schütz (2013), a postura crítica adotada por Marcuse em relação à amplitude emancipatória da razão não significa o abandono de seus potenciais inerentes, mas a necessidade urgente de se repensar a própria concepção de razão, que no horizonte do princípio do desempenho, é irreconciliável com a sensibilidade.

Porém, a libertação das forças de resistência não pode aparecer dentro das estruturas opressivas da sociedade industrial. Para isso, seria necessária uma mudança de direção no foco do progresso, e isso pressupõe a existência de alternativas, da sua experimentação, e é justamente essa experiência que é barrada na cultura estabelecida. Sua libertação esta previamente condicionada à restauração da dimensão cultural ameaçada pelo totalitarismo: a dimensão espiritual da autonomia (Marcuse, 1986).

Marcuse aponta para o fato de que a teoria social tem a capacidade e condições para, a partir da análise da sociedade e levantamento das alternativas possíveis, superar a realidade estabelecida e auxiliar no câmbio qualitativo da sociedade como um todo. Porém, a teoria crítica tem receio em se aventurar além de seus limites em virtude do temor em perder seu caráter científico. Para isso seria preciso que a teoria crítica fosse vista como guia da prática política, pois uma abstenção como a de Marx e Engels em elaborar conceitos concretos sobre as possíveis formas de libertação já não parecem justificadas (Marcuse, 1969).

Neste caso, a criação de um refúgio intelectual, livre das forças repressivas ao menos a nível subjetivo, assumiria a forma de um "elitismo" intelectual, uma retirada voluntária, quando, na verdade, uma real redefinição de cultura implicaria em uma intenção à luta contra as tendências mais poderosas que se mostram. Significaria a libertação do pensamento e da pesquisa do universo de adaptação estabelecido, a elaboração de métodos e conceitos capazes de superar racionalmente os limites dos valores estabelecidos pela sociedade (Marcuse, 1986).

Uma reorganização da cultura redefiniria também a função e objetivo da ciência hoje. Sua valorização dependerá fortemente não somente de suas verdades, mas também do seu impacto na vida das pessoas. A tecnologia tem sido usada como instrumento da política destrutiva, uma política que prima pelo aprisionamento do indivíduo em formas repressivas de labuta. Uma redefinição qualitativa da tecnologia teria como meta a pacificação da luta pela existência. Com vistas a promover a melhoria qualitativa da vida, a razão seria "a direção do 'ataque ao ambiente' que resulta do impulso tríplice: 1) de viver, 2) de viver bem, 3) de viver melhor" (Marcuse, 1978, p. 211). Conforme Fernandes (2012), o tipo de revolução de que Marcuse fala é uma revolução libertadora, uma mudança da consciência dos indivíduos que só pode ser levada a cabo por forças não repressivas.

Porém, para que surja esta nova consciência é preciso que se crie um âmbito diferente daquele da linguagem unidimensional da sociedade tecnológica, na qual as possibilidades de contestação da ordem sejam permitidas, "uma linguagem para definir e comunicar os novos 'valores"” (Marcuse, 1969, p.39). A negação radical da ordem existente corresponde cada vez mais à criação de uma linguagem peculiar e, neste sentido, o desenvolvimento de uma linguagem própria pelos grupos subculturais representa um instrumento tanto de contestação como de tomada de consciência.

O surgimento de uma nova sensibilidade, para Marcuse, pressuporia a mudança no emprego da ciência e da técnica, onde sua principal função em uma nova sociedade seria a de, em primeiro lugar, eliminar a exploração e a miséria em âmbito global. A consciência livre, guiada pela imaginação transformadora, conduziria uma nova prática em que a afirmação dos instintos de vida encontraria expressão racional no planejamento racional do tempo de trabalho socialmente necessário entre os vários ramos da produção, determinando assim prioridades de objetivos e seleções: não apenas o que se deve produzir, mas também a forma do produto (Marcuse, 1969).

A imaginação possui papel fundamental na redefinição da cultura, e tem por característica básica a contraposição à racionalidade científica moderna. Enquanto a primeira pode ser vista como matéria prima da arte e da transformação qualitativa, a segunda, em contrapartida, se caracteriza pela ênfase dada à quantificação e exatidão. Enquanto manifestação da sensualidade, a imaginação criadora da arte possui a capacidade de guiar uma racionalidade não-repressiva: "a imaginação entra em acordo com as noções cognitivas do entendimento, e esse acordo estabelece uma harmonia das faculdades mentais que é a resposta agradável à livre harmonia do objeto estético" (Marcuse, 1975, p.160). Desse modo, a imaginação livre característica da arte pode ser utilizada para a transformação da racionalidade instrumental, substanciando-se em uma racionalidade fundada essencialmente em Eros. Nesse caso, sua principal função será o desenvolvimento de uma ciência e tecnologia livres para realizar as potencialidades humanas na proteção e gozo da vida (Marcuse, 1969).

A técnica poderia, então, devir da arte, e a arte tenderia a formar a realidade, invalidando a oposição entre imaginação e razão, baixas e altas faculdades, pensamento poético e científico. Para Marcuse (1969), encontra-se aí a possibilidade 
do surgimento de um novo princípio da realidade, não mais dependente das exigências do princípio do desempenho ou curvado sob a égide da mais-repressão. A não existência da sobre-repressão instintual possibilitaria a junção de uma nova sensibilidade a uma inteligência científica marcada pela necessidade de libertação. Essa racionalidade fundada em um Ethos estético teria na dimensão do belo, uma referência essencial na fundamentação da nova racionalidade. A beleza como poder de anular e imobilizar a violência, assim como no mito de Medusa, aquela que paralisa o agressor pela beleza.

Conforme Fernandes (2012), a transformação do mundo pela forma estética pode ser entendida também como uma nova determinação da realidade, caracterizando-se pela junção da natureza e da liberdade. É nesse estágio que a arte pode contribuir para a transformação social, fornecendo as imagens para uma redefinição da realidade. Em um mundo regrado pelas leis de mercado e pela competição irrestrita, a dimensão estética poderia servir como uma espécie de calibrador para uma sociedade livre (Marcuse, 1969). Conforme Marcuse, as qualidades estéticas teriam como elemento inerente a qualidade de poder se constituir apenas a partir da luta contra aquelas instituições que negam o seu desenvolvimento. Ou seja, possuem como caráter básico o seu conteúdo social de negação.

\section{O Papel da Educação no Processo de Redefinição da Cultura}

Porém, para que tal racionalidade surja é primeiro necessário fazer brotar nos explorados a consciência que lhes permita vislumbrar sua real condição, assim como as falsas necessidades que perpetuam sua dependência ao sistema. Segundo Marcuse (1969), tal ruptura só poderá ser resultado de uma educação política em ação, sem a qual qualquer revolução poderia se transformar em uma contrarrevolução. No esquema de redefinição da cultura proposto por Marcuse a educação tem papel essencial. Através dela seria criada uma esfera de resistência à dominação imposta pelo sistema econômico e positivista.

Marcuse (1986) salienta para o fato de termos presente que uma educação realmente transformadora terá que ir além das escolas e universidades, terá que ser uma educação tanto na teoria como na prática e, sobretudo, na prática política. Porém, não no sentido de politizar o sistema de ensino, mas sim de criar uma contra-política, oposta à política estabelecida. Ou seja, cabe à educação fomentar condições que permitam aos sujeitos questionar a sociedade em que vivem, dando margem a possibilidade de gestão de novas formas de existência.

Em um mundo onde o controle da subjetividade é mantido pela satisfação real das necessidades por um lado, e pela manipulação e administração massiva das falsas necessidades por outro, a educação seria um instrumento importante na luta contra as formas mutiladas de experiência e consciência fabricadas pelo establishment. Neste contexto, Marcuse aponta para o fato dos intelectuais, que embora não possam constituir o agente histórico da mudança, serem as bases sobre as quais deve partir a mudança (Marcuse, 1986), ou seja, os catalizadores dos processos de contestação e libertação da sociedade opulenta. Esse grupo torna-se de fundamental importância na medida em que a libertação exige dos homens uma nova consciência e sensibilidade, assim como novos valores, onde somente serão aptos a levá-la adiante os grupos sociais que, por sua posição privilegiada, podem atravessar o velo material da comunicação e do doutrinamento de massas.

No âmbito educacional, a educação para a autonomia intelectual e emocional seria mais do que um mero desafio em virtude de pressupor de antemão a violação de alguns dos tabus democráticos mais fortes, pois a atual democracia se esconde atrás de uma pseudodemocracia, mais importada em deter o desenvolvimento das necessidades sob o disfarce de desenvolvêlas (Marcuse, 1986). Isso significaria ir contra as tendências mais poderosas desta sociedade para que a verdadeira libertação do pensamento e da aprendizagem superem racionalmente os limites do status quo.

No ideário marcuseano, se os problemas da atual sociedade têm seu foco na concepção de razão inerente à ciência e ao progresso, uma redefinição guiada pelo ideário de valorização das esferas teóricas e transcendentes do pensamento, seria capaz de sustar a mudança qualitativa da razão na medida em que não se sacrifica frente ao empirismo e ao positivismo (Marcuse, 1986). Neste sentido, a ênfase voltar-se-ia para as ciências humanas, para a teoria "pura", a filosofia especulativa, etc. Pois, enquanto pensamento não-operativo, as humanidades representam um escopo teórico que têm como caraterística básica a oposição ao positivismo e, consequentemente, formam uma esfera antagônica à atual ciência instrumental.

Conforme Marcuse (1986), o aprendizado baseado nas premissas tecnicistas serve para cercar as raízes da autodeterminação da mente do sujeito, de forma que exige uma dissociação crítica do universo da experiência. $\mathrm{O}$ estudante é, assim, orientado a compreender as condições e possibilidades estabelecidas somente nos termos e nas condições dadas, sendo que seus pensamentos e ações ficam restringidos por um pragmatismo científico formado por uma experiência mutilada. Sem a crítica da experiência o estudante fica privado dos métodos e instrumentos que lhe permitem avaliar e compreender a sociedade e a cultura em seu conjunto, no interior do continuum histórico em que esta sociedade deforma e nega suas próprias possibilidade e promessas.

Neste caso, Marcuse atesta para o fato de que uma redefinição da cultura necessitaria também da criação de um refúgio 
intelectual onde a ciência teorética se veria livre das influências da racionalidade instrumental, onde a ênfase seria dada não mais à ciência instrumental, desejosa de resultados quantitativos, mas sim a métodos e conceitos capazes de superar os limites dos valores estabelecidos. Esta educação teria o poder de preparar o fundo espiritual para uma hierarquia qualitativamente diferente de valores e poder, somente sendo possível por parte de um governo desejoso e capaz de contestar a tendência política e a econômica dominante (Marcuse, 1986).

Para Marcuse, uma das formas de preservação e desenvolvimentos dos métodos de pesquisa e do pensamento não operativo das ciências humanas, viriam a se concretizar sob a forma da criação de universidades "elite", separadas das escolas vocacionais, que manteriam e ampliariam seu caráter de formação vocacional. O termo "elite" se refere a uma escolha realizada nas escolas vocacionais onde seriam escolhidos unicamente por mérito, ou seja, segundo a inclinação e a capacidade para o pensamento teorético (Marcuse, 1986). O requisito indispensável à sua criação e funcionamento seria a independência financeira total, ficando livres tanto da perniciosa influência da iniciativa privada quanto da educação militar, impedindo uma condução nociva da ciência. A ênfase no ensino em tal instituição seria a sobrevivência e preservação do pensamento teorético e negativo, capaz não só de questionar as atuais formas de crescimento e desenvolvimento científico, como também fazer surgir a consciência de sua condição, abrindo caminho para o desmantelamento das falsas necessidades.

A criação de novas necessidades, assim como a libertação instintual e o consequente surgimento de uma nova sensibilidade, na obra marcuseana é revestida pela ideia de uma educação estética que se converte em formação: construção de um pensamento crítico, que no contato com os elementos estéticos, fomenta uma práxis transformadora. Em um texto de 1967 intitulado A arte na sociedade unidimensional, Marcuse apresenta brevemente o motivo que o levou a se ocupar com o fenômeno da arte: "aconteceu por uma espécie de não-esperança ou desespero. Desespero ao perceber que toda a linguagem, toda a linguagem prosaica e particularmente a linguagem tradicional, de algum modo parece ter morrido" (Marcuse, 1982, p. 245, grifos do autor). Ela se tornou incapaz de comunicar as situações que se desenrolam frente a nossos olhos, assim como parece ter se tornado inteiramente obsoleta em relação às novas formas de protesto e recusa apresentados pela arte, principalmente pela busca surrealista em encontrar uma linguagem nova. Neste sentido, para Marcuse, somente a linguagem da arte parece ser livre, pura e verdadeira para expressar as verdades que não podem ser ditas livremente no mundo reificado das mercadorias; enfim, "a sobrevivência da arte pode vir a ser o único elo frágil que hoje conecta o presente com a esperança do futuro" (Marcuse, 1982, p. 246).

No campo estético, a tradição do protesto e da recusa permanece por direito próprio, como parte essencial e primordial de toda a arte pura, representada até mesmo na arte mais afirmativa do período burguês. A arte só pode comunicar as verdades estéticas na medida em que se situa em uma esfera antagônica à realidade, fora do domínio da práxis e da produção material, representando a realidade através desta outra linguagem: "a arte tem sua própria dimensão da afirmação e negação, uma dimensão que não se pode coordenar com o processo social de produção" (Marcuse, 1977, p.33). É na dimensão estética que é preservado o âmbito da crítica por excelência: o pensamento negativo. Ao apresentar o mundo como ficção, a arte o faz surgir tal como ele é, pois “só no 'mundo ilusório' as coisas parecem o que são e o que podem ser. Em virtude desta verdade, o mundo é invertido - é a realidade concreta, o mundo vulgar que agora aparece como realidade falsa, ilusória, enganadora" (Marcuse, 1977, pp.61-62).

A dimensão estética como base para a construção de uma nova realidade, assumiria para si a tarefa do retorno de Eros à razão, a volta da dimensão erótica no conjunto da razão humanizada. A nova racionalidade implicaria, diferentemente da ciência instrumental da era capitalista, na possibilidade de eliminar a escassez, a servidão do trabalho e a injustiça, ou seja, implicaria na possibilidade de se pacificar a luta pela existência (Marcuse, 1986). Em uma educação voltada para este fim, a dimensão do sensível presente na arte e na cultura seriam requisitos básicos para a criação de um âmbito onde o objetivo primordial seria a mudança qualitativa da humanidade para um estado de total pacificação.

Conforme Marcuse (1986), a arte hoje deve também ser considerada como uma técnica, no sentido prático do termo, pois agora mais do que nunca, sua atividade é mais a de fazer e refazer coisas do que pintar quadros. Sendo assim, ela pode e deve ser considerada uma técnica, porém completamente oposta à atual concepção de tecnologia, ou seja, baseada no poder da imaginação e da estética, infinitamente mais humana, pronta para ser inserida como pilar mestre da transformação da moderna razão repressiva. É importante atestarmos que para Marcuse (1986) a dimensão estética não é fonte de transformação objetiva clara e rápida, ela apenas pode libertar a percepção e a sensibilidade necessárias para a transformação. A partir do momento em que uma real mudança houver ocorrido, a arte passa a guiar a construção de uma nova sociedade que, consequentemente, também implica no surgimento de uma nova racionalidade.

Nesse caso, pode-se notar a importância dada por Marcuse para a subjetividade, pois é sob ela que se assentam as principais opções de construção de uma sociedade mais justa e humana. Conforme o filósofo, a subjetividade pode ser considerada em si mesma como política. Isto é, na medida em que a emancipação das condições dadas de vida e sua transcendência em direção de mais liberdade, alegria e tranquilidade são impulsos que constituem necessariamente a subjetividade, esta nada mais é do que um projeto interno dos indivíduos que introjetam e confrontam sua sociedade. 
Focando na libertação subjetiva como base para a transformação da existência objetiva, a educação estética desponta na obra marcuseana como um fator de suma importância na redefinição da cultura estabelecida. Nela seriam dirigidos todos os esforços que visam a uma constituição da subjetividade livre e sensível, baseada na pureza e na força antagônica da racionalidade estética, pois "enquanto a arte preservar, com a promessa de felicidade, a memória dos objetivos inatingidos, pode encontrar, como uma 'ideia reguladora', na luta desesperada pela transformação do mundo" (Marcuse, 1977, p.75). Contra toda a reificação e dominação dos indivíduos pelas condições objetivas, a arte representa sobretudo o objetivo derradeiro de todas as revoluções: a liberdade e a felicidade do indivíduo.

\section{Considerações Finais}

Marcuse por vezes é considerado um dos autores mais polêmicos da contemporaneidade em virtude das críticas contundentes dirigidas ao capitalismo e, consequentemente, à sociedade que o adota. É daí também que surgem a maioria das críticas dirigidas a ele, como é o caso de Vivas (1972), que o acusa de niilista, extremista e possuidor de um ódio irascível contra a sociedade que tão bem o tratou. Aqui, pode se notar, antes de tudo, que a crítica encabeçada por Vivas não passa de uma personificação da resposta dada pelo capitalismo à ameaça representada pela filosofia marcuseana, que vê na libertação da consciência a possibilidade da eliminação do sistema de sujeição das necessidades.

Deprende-se, também, da maioria das críticas à Marcuse, a acusação de totalitarismo, como é o caso de Nicolas (1971). Este, embora não impulsionado pela crítica ao filósofo, caracteriza Marcuse como um pesquisador simpatizante das políticas totalitárias (tal como foi classificado Platão ante seus críticos), como demostra na seguinte frase: "e nós conhecemos a nostalgia que Marcuse sente em relação às sociedades em que a injustiça era flagrante, tal como a escravatura" (Nicolas, 1971, p.198). Tanto a afirmação de Nicolas, assim como a de Vivas, só pode ser classificada como um reducionismo crítico, pois ataca um pensador preocupado com a libertação integral do homem, tanto a nível subjetivo quanto objetivo, a partir de um conceito reificado de democracia. Ou seja, a democracia e a liberdade são entendidas unicamente pelo desejo irrestrito e carregado de ideologia capitalista que as massas alienadas exprimem, concentrando-se, sobretudo na liberdade e na democracia quanto à escolha das mercadorias. Marcuse afirma justamente que o programa de libertação das necessidades suporia a violação de alguns dos tabus democráticos mais fortes, conquanto a cultura democrática predominante "detém o desenvolvimento das necessidades sob o disfarce de promovê-las e detém o pensamento e a experiência pela aparência de estendê-las em todas as partes e para todos" (Marcuse, 1986, p. 73).

Se por um lado a filosofia de Marcuse atacou vorazmente o sistema capitalista, era por ser este a fonte da maioria da servidão a que é submetida a humanidade, ou seja, um sistema que possui como base de sustentação e funcionamento a manutenção do sistema de sujeição e reificação. Além do mais, tal crítica não pode jamais ser classificada com niilista, pois ao passo que apresenta a humanidade como presa às amaras do lucro, também oferece uma ampla perspectiva de superação de tal estado através da superação do conceito errôneo de razão adotado pela moderna sociedade industrial. Conforme Marcuse, a substituição desta concepção por outra baseada na bidimensionalidade de Eros e Logos que se expressa mais claramente na cultura e na arte, representaria a elevação da humanidade a um patamar de crescimento qualitativo, em que a tecnologia seria tão somente dirigida à pacificação da atividade de satisfação das necessidades.

Segundo Marcuse (1973), a revolução no âmbito cultural, se estende para muito além da reavaliação artística, pois ataca as raízes do capitalismo no próprio indivíduo. Isso se justifica na medida em que a subjetividade passa a se revestir de uma característica política, representando os impulsos básicos dos sujeitos. Dessa forma, a sua constituição a partir da racionalidade estética, prepararia e impulsionaria a construção de uma subjetividade livre da reificação, que por sua vez seria responsável pela reconstrução objetiva do mundo sob a égide da não-agressão e não-exploração. A estética seria o pilar fundamental sob o qual se erigiria a nova racionalidade, o princípio de Eros se uniria novamente ao conceito de razão, colaborando na construção de uma racionalidade que teria como função o alcance da emancipação.

As teses marcuseanas acerca da necessidade de valorização dos âmbitos não-científicos do pensamento recaem na premissa central da transformação da concepção de razão adotada pela sociedade estabelecida, o que torna extremamente relevante o estudo da obra de Marcuse na contemporaneidade. A sua utilização pela teoria educacional promove um debate profícuo em torno da ideia de razão emancipatória. A ênfase de Marcuse na crítica, não somente às condições objetivas da dominação, mas também à dominação embutida nas formas subjetivas da racionalidade social possibilita uma teoria educacional que coloque como objetivo principal a crítica e a resistência às formas pelas quais a racionalidade social é instrumentalizada com o objetivo de manutenção de uma determinada estrutura de poder. Nisso, aponta-se a importância de que uma prática política de transformação da realidade sem a permanente crítica da racionalidade social, sem a transformação da subjetividade, não é uma prática emancipatória. 


\section{Referências}

Benjamim, W. (1982). A obra de arte na época de sua reprodutibilidade técnica. In L. C. Lima (Org.), Teoria da cultura de massa (3ª ed., pp.209-243). São Paulo: Paz e Terra.

Carnaúba, M. É. C. (2009). Marcuse e a psicanálise: Mais-repressão e o princípio do desempenho. Revista.doc, 10(7), 119137.

Doria, F. A. (1974). Marcuse vida e obra. Rio de Janeiro: Paz e Terra.

Fernandes, P. I. B. (2012). Herbert Marcuse e “As imagens de libertação”. Educação e Filosofia, 26(52), 527-549.

Freud, S. (2010). Obras completas: O mal-estar na civilização, novas conferências introdutórias e outros textos (19301936) (Vol. 18). São Paulo: Companhia das Letras. (Originalmente publicado em 1930).

Marcuse, H. (1969). Un ensayo sobre la liberación. México: Cuadernos de Joaquín Mortiz.

Marcuse, H. (1973). Contra-revolução e revolta. Rio de Janeiro: Zahar Editores.

Marcuse, H. (1975). Eros e civilização: Uma interpretação filosófica do pensamento de Freud (6a ed.). Rio de Janeiro: Zahar Editores.

Marcuse, H. (1977). A dimensão estética. Lisboa: Edições 70.

Marcuse, H. (1978). A ideologia da sociedade industrial: O homem unidimensional (6 $6^{\mathrm{a}}$ ed.). Rio de Janeiro: Zahar Editores.

Marcuse, H. (1982). A arte na sociedade unidimensional. In L. C. Lima, Teoria da cultura de massa. São Paulo: Paz e Terra.

Marcuse, H. (1986). Ensayos sobre política y cultura. Barcelona: Planeta-Agostini.

Marcuse, H. (1997). Sobre o caráter afirmativo da cultura. In H. Marcuse, Cultura e Sociedade. Rio de Janeiro: Paz e Terra.

Marx, K. (2008). Contribuição à crítica da economia política. São Paulo: Editora Expressão Popular.

Nicolas, A. (1971). Marcuse ou a busca de um universo transprometeico. Lisboa: Estúdios Cor.

Schütz, R. (2013). Por um outro princípio de realidade: Novos lugares e motivos sociais da negação segundo Herbert Marcuse. Educação e Filosofia, 27(54), 699-718.

Vivas, E. (1972). Marcuse em julgamento. Rio de Janeiro: Edições Bloch.

\section{Endereço para correspondência}

Vivian Baroni

End.: Rua Júlio Longhi, nº 345, Bairro São José, Passo Fundo. Rio Grande do Sul, CEP 99052-300.

E-mail: vivianbaroni@hotmail.com 